\section{A REPORT ON THE FIRST YEAR'S WORK OF A CLINIC FOR SYPHILITIC CHILDREN.*}

\section{By REGINALD C. JeWESBURY, M.A., M.D. Oxon.,} F.R.C.P. LOND.,

PHYSICIAN IN CHARGE OF THE CHILDREN'S DEPARTMENT AT ST. THOMAS'S HOSPITAL, LONDON.

RATHER more than a year ago it was decided to form a special clinic in the Children's Department of St. Thomas's Hospital for children suffering from syphilitic infection. One morning a week has been set aside for this clinic, which draws its cases from the rest of the children's department and other special departments, including that for venereal disease, under the direction of Colonel L. W. Harrison, D.S.O.

I wish to confine my remarks to the findings of this clinic. During the first 12 months a total of 145 children were seen whose mothers were known to be syphilitic. Of these, 9 moihers became infected after the births of their children, hence the disease in these children was acquired. Of the remaining 136 mothers, infected before the birth of the child, 47 had treatment before or during pregnancy. In 89 cases the mothers had received no treatment previous to the birth of the child.

Incidence.

First with regard to the incidence of the disease in families as it affects the children born of syphilitic parents; in about 50 per cent. of the cases the disease was most marked in the earlier pregnancies, and appeared to become gradually attenuated, apparently healthy children coming at the end of the family (Regular type). But in just as many cases children apparently free from infection cropped up irregularly in the midst of definitely syphilitic children and miscarriages (Irregular type).

$$
\text { Examples of Regula, Type of Family. }
$$

$$
\text { A. (i.) }
$$

1, 2, 3. Healthy children.

Infection-

4, 5. Premature child, lived one day.

7. 8. Stillborn. 9." Miscarriage.

10, 1i. Apparently healthy children. W.R. negative.

$$
\text { A. (ii.) }
$$

1. Died at 18 months. "Fits."

2. Miscarriage at $4 \frac{1}{2}$ months.

3,4 . , 6 weeks.

5. Twins. \{ , 'syphilitic child; Wassermann positive.

6. Twins. $M$, apparently healthy ; , negative.

In this case the syphilitic twin showed obvious clinical signs of disease, whilst the other one was free from all such signs, and the Wassermann reaction was repeatedly negative up to 6 years of age.

\section{Examples of the Irregular Type of Family.} B. (i.)

1. Seven-months' child; died at 3 days.

2. Eight

3, 4. Stillborn.

5. Now living, aged 19 years; healthy.

6. stillborn. 8. 'Died at' 7 days."

9. Stillborn; macerated fotus. 10,11. Miscarriage.

12. Now living, aged 9 years; W.R. +; interstitial keratitis.

13, 14. Miscarriage. 15. Twins, stillborn. 16. Miscarriage.

I. Died at 9 months.

$$
\text { B. (ii.) }
$$

Then six miscarriages

8. Died at 31 years ("heart disease").

9. Now living; W.R. +++

10. Died at 2 years.

11. ", "11 weeks ("bronchitis").

12. " " $2 \frac{1}{2}$ years ("wasting").

13. Now living, aged 4 years; apparently healthy; W.R. negative.

14. Died at 14 months (blind).

15. Now living, aged 1 year; W.R. +++ .

Mother, W.R. ++++ .

Treatment begun since birth of last child.

* A summary of this work formed a contribution to the recent discussion on congenital syphilis lield by the Children's Section of discussion on congenital syphi
the Royal Society of Medicine.

\section{Signs in the Child.}

(1) A few children of syphilitic mothers who had received no treatment were quite free from any signs, and have given negative Wassermann reactions even up to the age of 10 to 14 years.

(2) Many children showed the usual signs seen in typical congenital syphilis, in whom rash and snuffes appeared two to eight weeks after birth.

(3) In a certain number of children seen, in whom there was no history of previous symptoms, symptoms developed late, after the fifth or sixth year-i.e., "lues tarda." This group amounted to 10 per cent. of all cases examined.

In these children lesions of the following structures were present: bones-periostitis; joints-synovitis; eyes - interstitial keratitis ; brain-particularly affecting mental condition ; ears-deafness; and teeth.

\section{Cases Illustrative of Late Changes.}

Case 1.-F. F., boy, aged 12 years. Family history: two stillborn children previous to birth of this child. The latter healthy at birth; full time; no rash or snuffles; apparentl normal child up to 5 years. First changes were mental, lack of concentration, loss of memory, \&c. Boy much undersized; no definite physical stigmata. Skin, teeth, and bones -no signs. Eyes: pupils sluggish to light, equal. No keratitis; fundi normal. Viscera: spleen and liver not enlarged; reflexes normal; no ataxy. W.R. of blood and cerebro-spinal fiuid ++ .

CASE 2.-J. R., boy, aged $11 \frac{1}{3}$ years. Family history as follows: (1) Died soon after birth; (2) stillborn ; (3) died at birth; (4) stillborn; (5) the patient, W.R. ++++ ; (6) living, W.R. $+++;$ (7) living, W.R. $+++;(8)$ living, W.R. - . No definite notes of mother's treatment; said to have had some treatment five years before birth of this child. Child full time, no signs during infancy. "Meningitis" at 2 years, very ill for two months, good recovery, well up to 9 years, then complained of frequent headaches, became dull and stupid. At 10 years became clumsy and began to lose use of limbs. Sight good. Not deaf. A big, welldeveloped boy, coarse features, high palate, very dull Slight glandular enlargement. No other signs. Fundi normal. Reflexes normal. W.R. reduced after seven injections N.A.B. and mercury by mouth.

$$
\text { rassermann Reaction as a Means of Diagnosis. }
$$

This has been found to be a very valuable and reliable test. In the case of syphilitic infants, the reaction is often negative during the first few months of life and later becomes positive. In cases where the test is negative at first it has been repeated every six months until the child is 2 years old. The reactions have been carried out in the Pathological Department under the direction of Professor L. S. Dudgeon.

\section{Effect on Child in Untreated Syphilitic Mother.}

Seventy-seven families investigated; total number of pregnancies, 322 . Of these $97(30 \cdot 2$ per cent.) resulted in miscarriage or stillbirth, $73(22 \cdot 8$ per cent. resulted in death in infancy or early childhood, and 152 (47.0 per cent.) were still alive at time of investigation. Mortality of children born alive $=32.4$ per cent.

Effect on Child when the Mother was Treated Before or Inurint Pregnancy.

Number of cases investigated, 43. Treatment varied from three courses of N.A.B. and mercury down to a few doses of mercury as late as the ninth month of pregnancy. Number of cases treated effectively before or during the early stages of pregnancy, 39. Total number of pregnancies, 53. Of these, 1 resulted in miscarriage, 6 in death in infancy, 46 in living children. There were therefore 87 per cent. of living children at time of examination. Actual mortality of this series of children was 11.5 against 32.4 of the former series. It was found that where the treatment of the mother was not begun until the seventh month or later of pregnancy that the child usually showed wellmarked evidence of syphilis, but in the majority of mothers who had received treatment not later than the fifth month of pregnancy the children were born apparently healthy and gave negative Wassermann reactions.

CASE 1.-Mother treated two N.A.B. injections at eighth month and $\mathrm{Hg}$ by mouth. Child showed syphilitic lesions at 3 months.

CASF 2.-Mother treated six N.A.B. injections at seventh and eighth months.and $\mathrm{Hg}$ by mouth. .Child syphilitic and W.R. + + at 4 months. 
CASE 3.--Mother treated sixth, seventh, and eighth month with seven N.A.B. injections and $\mathrm{Hg}$ injections. Child healthy and W.R. negative up to 10 months.

CASE 4.-Mother, who had had four miscarriages and four children dying early in infancy with strongly positive W.R., was treated fourth to eighth month with five N.A.B.injections and $\mathrm{Hg}$ by mouth. Child born healthy; under observation for one year and nine months, remaining healthy, and W.R. negative.

\section{Effect of Ireatment on the Child.}

Method.-In most cases novarsenobillon was given intramuscularly into the buttock. Dose $0.015 \mathrm{~g}$. per kilo of body weight, with gradually increasing doses, at intervals of one week, for six injections. In some cases a second course has been given at an interval of about three months. Simultaneously, mercury in the form of hydrarg. cum eret. in 1-1 gr. doses by the mouth t.d.s., this being kept up regularly. In a few severe cases mercurial inunction has been ordered. In the majority of cases the N.A.B. injections have caused no kind of ill-result. A few cases were followed by pain for some time after, and induration at the site of injection. No case has been followed by suppuration. In a few cases a slight general reaction was set up, with headache, drowsiness, and vomiting, nsually not lasting longer than 12 hours. In theolder children the N.A.B. has been given intravenously.

Taking blood from child for Wassermann reactions.-(1) From vein of scalp or arm or internal jugular vein depending on age; (2) from heel into capillary tube; (3) from longitudina sinus through anterior fontanelle. (This method only in a few cases.)

Effect of Treatment on IIassermann Reaction in the Child.

In 30 cases receiving full course of N.A.B. and $\mathrm{Hg}$ and kept under observation the W.R. has been changed from "positive" to "negative." In some a strongly positive reaction has been reduced. In some the reaction has not been affected after a course of six injections of N.A.B. and Hg. The cases benefiting least by treatment with regard to the Wassermann reaction and physical signs are those of the late manifestations affecting children from 5 to 10 years, and especially those cases in whom the central nervous system is involved.

Effect of Treatment on Clinical Sigms of Disease in the Child.

Early signs quickly cleared up, especially rashes and condylomata. Rhinitis less easily cured. Usually rapid improvement in general condition. with steady gain in weight. Liver and spleen reduced in size.

Late cases. - No case of disease of the central nervous system affected. Interstitial keratitis; some definite improvement of vision in several cases. Periostitis definitely improved.

The number of cases is rather small so far, but I hope this analysis of them will be considered worthy of recording. I am indebted to several kind assistants in this work, but particularly to Dr. J. C. Spence, who has kept very careful notes of every case seen and has also helped with the clinical work.

\section{SIMILARITY OF FFFECTS PRODUCED BY} ABSENCE OF VITAMINS

AND BY EXPOSURE TO $X$ RAYS AND RADIUM.

BY W. CRAMER, D.SC. EuIN., PH.D. BERL., M.R.C.S.,

\section{A. H. DREW, D.SC. LOND.,}

AND

J. C. MOTTRAM, M.B. LoND., D.P.H.

From the Imperial Cancer Research Fund, and from the Radium Institute, London.)

From the fact that the absence of vitamins from the diet leads to a gradual decline of the higher animals, and if sufficiently continued is incompatible with maintenance of life in these animals, the important generalisation has been drawn that vitamins are essential for the life of the cell. Histological investigations of the tissues and organs of animals kept on such a diet have so far failed to reveal any lesion sufficiently gross and affecting a vital organ which would account for the decline or the death of the animals. Our own observations on mice and rats kept on a diet completely free from vitamins have, with the one exception presently to be mentioned, given the same result. Even the finer cytoplasmic structure, as expressed in the condition of the mitochrondria, is not alteied deeply enough to account for the condition of decline and the death of the animals. Nor does the general condition produced by the absence of vitamins help to an understanding of the manner in which they act. For the general condition of these animals is simply one of inanition, and many of the changes described as occurring in the tissues of animals kept on a vitamin-free diet are similar to, or identical with, those produced by chronic starvation. The hypertrophy of the adrenals may be quoted as an example. ${ }^{12}$

It appears to us that this hypertrophy of the adrenals in the absence of vitamins is an argument against the generalisation that vitamins are essential to the life of every cell. They do not appear to be essential to the life of either the cortical or the medullary cells of the gland. Subsidiary assumption would have to be made, for instance, that this organ is distinguished by a large store of vitamins. But such an assumption is negatived by the experimental test, ${ }^{3}$ at least as regards the fatsoluble vitamin, and has never been demonstrated for the water-soluble vitamin. In mice and rats kept on a vitamin-free diet very active growth changes, as evidenced by the occurrence of mitoses, have also been observed in the cells of Lieberkithn's follicles, even in the last stages of avitaminosis. Similarly transplanted tumours show active growth in animals kept on a vitamin-free diet and suffering severely as the result of the absence of vitamins.

Vitamins Unnecessary for Life of Individual Cells.

The generalisation that vitamins are necessary for the life of the cell has been extended so as to cover even the lower forms of life, plants, bacteria, yeast cells, \&c. The recent work of Lumière has shown that so far as these lower forms of life are concerned this view was based on faulty experimental observations. It is therefore important to realise that what has been experimentally established is the fact that vitamins are essential for the maintenance of life of a highly differentiated animal as a whole, but not necessarily, or probably, of its individual cells.

There is, however, one tissue which is specifically and profoundly affected by the absence of vitamins from the diet-namely, the lymphoid tissue. In mice and rats kept on a diet completely free from vitamins there is a great atrophy of the lymphoid tissue, which is obvious even to the naked eye. The gpleen is shrunk to a narrow ribbon; the thymus, which even in adult rats and mice remains relatively a large organ flling the upper part of the thorax and covering the base of the heart, becomes so small as to be hardly visible. The Peyer's patches, which are prominent in normal animals, are difficult to identify with the naked eye. Microscopically these organs, especially the spleen, are found to contain very few leucocytes. The ordinary lymph glands may not be macroscopically smaller than normal, but under the microscope are found to be almost bare of lymphocytes. They consist almost entirely of endothelial cells and large empty 1ymph spaces. The blood picture, as shown by a differential count, shows a reduction in the number of lymphocytes and an increase in the number of polymorphonuclear leucocytes.

Extreme Reduction of Number of Lymphocytes.

As an example of the degree to which the lymphocytes muy be affected, the following extreme figures obtained

\begin{tabular}{c|c|c|c|c|c}
\hline- & $\begin{array}{c}\text { Lympho- } \\
\text { cytes. }\end{array}$ & $\begin{array}{c}\text { Large } \\
\text { mono- } \\
\text { nuclears. }\end{array}$ & $\begin{array}{c}\text { Poly- } \\
\text { morphs. }\end{array}$ & $\begin{array}{c}\text { Mast } \\
\text { cells. }\end{array}$ & $\begin{array}{c}\text { Eosino- } \\
\text { philes. }\end{array}$ \\
\hline $\begin{array}{c}\text { Avitamin yat } \\
\text { No. 130. } \\
\text { Normal rat. }\end{array}$ & $\begin{array}{c}\text { Per cent. } \\
25\end{array}$ & $\begin{array}{c}\text { Per cent. } \\
15\end{array}$ & $\begin{array}{c}\text { Per cent. } \\
57\end{array}$ & $\begin{array}{c}\text { Per cent. } \\
2\end{array}$ & $\begin{array}{c}\text { Per cent. } \\
1\end{array}$ \\
\hline $\begin{array}{c}\text { Avitamin mouse } \\
\text { No. 140. } \\
\text { Normal mouse. }\end{array}$ & 64 & 7 & 37.5 & 1.3 & 0.2 \\
\hline
\end{tabular}

in a mouse and a rat in the final stages of avitaminosis may be given. These animals did not suffer from any intercurrent infection. The differential counts give figures varying a good deal for different individual animals, and the examples given represent the extreme 